\title{
Asthma treatment, perceived respiratory disability, and morbidity
}

\author{
C V E Powell, R A Primhak
}

\begin{abstract}
An entire school year of 8-9 year old schoolchildren in Sheffield were surveyed using the core questions of the international study of asthma and allergies in childhood in order to assess the morbidity associated with diagnosed asthma. Of 5321 children surveyed, replies were obtained from $4539(85 \cdot 3 \%)$. A current diagnosis of asthma was reported in 466 $(10 \cdot 3 \%)$, and a further $6 \cdot 4 \%$ reported symptoms compatible with significant undiagnosed asthma. A validated questionnaire was used to assess symptoms and perceived disability in $336(72 \cdot 1 \%)$ of the children with diagnosed asthma. One third reported symptoms every day or most days, while $15 \cdot 3 \%$ reported frequent nocturnal symptoms. There was no significant difference in reported symptoms between those receiving inhaled steroids, sodium cromoglycate, or no prophylaxis. Despite this, parents of children receiving inhaled steroids perceived more disability, and worried more about their children's health. It is concluded that perceived symptoms and morbidity are high in children with diagnosed asthma, and speculate that level of treatment is determined by parental tolerance of symptoms as much as by the symptoms themselves.

(Arch Dis Child 1995; 72: 209-213)
\end{abstract}

Keywords: asthma, morbidity, parental attitudes.

Asthma is the commonest chronic disease of childhood, ${ }^{1}$ and it is important to assess accurately the impact and community morbidity of such a widespread disease. Some years ago Peckham and Butler used the national child development study to assess the social impact of asthma and wheezy bronchitis in 655 children at the age of 11 , with particular reference to behaviour and educational attainment. $^{2}$ The main problems they identified were increased school absence and abnormal parental rating of behaviour. School absence in wheezy children was studied in more detail by a community survey in Croydon, ${ }^{3}$ which found that over half the children with asthma reported school absence due to wheeze, and one eighth had a serious problem with absence. A large market research survey has recently reported considerable morbidity in children with asthma and their families. ${ }^{4}$ In most cases, studies have devised their own questionnaires to assess a few aspects of respiratory morbidity. We have recently surveyed the respiratory morbidity of all children in one school year in Sheffield. ${ }^{5}$ Using this relatively complete community survey and a previously standardised and validated respiratory morbidity score ${ }^{6}$ we have studied the perceived morbidity of 9 year old children suffering from diagnosed asthma, and its relationship to prescribed medication.

\section{Methods}

PRELIMINARY SURVEY

All children in one school year (aged 8-9 years) were surveyed between September 1991 and March 1992. The questionnaire circulated was designed to identify both children diagnosed as having asthma, and those with a history of chronic respiratory symptoms but as yet not diagnosed. It contained the core questions of the international study of asthma and allergies in childhood (ISAAC). ${ }^{7}$ The questionnaire was circulated by the primary schools to the parents of all children, and translations in Urdu, Bengali, and Chinese were available. Non-responders were sent a second questionnaire two months later.

All children who were described by the parents as having asthma at the time of the questionnaire were included in a second, more detailed survey.

\section{ASTHMA MORBIDITY SURVEY}

The parents of all children with asthma were asked to complete a respiratory morbidity questionnaire. ${ }^{6}$ This questionnaire asks about the frequency of five daytime symptoms and three night symptoms in the previous three months. It also contains nine questions that ask the parents to rate the impact of the disease on both the child and the family. Each symptom or disability is rated on a five point scale: 'never', 'few days', 'some days', 'most days', and 'every day', with a possible score of between 0 and 4 . This gives three subscores: day symptoms (maximum possible 20 ), night symptoms (maximum possible 12), and perceived disability (maximum possible 36 ). The questionnaire has good content validity and internal reliability. ${ }^{6}$ We added a further question to assess parental attitudes: 'I worry about my child's health ...,' with the same possible responses.

The prescribed treatment for each child was recorded, and the place of regular medical care was also ascertained. Each child was asked to complete a Piers-Harris questionnaire to assess self esteem. ${ }^{8}$ 
Table 1 Symptoms reported in the previous 12 months in 466 children with and 4073 children without a current diagnosis of asthma; figures are number/denominator (\%)

\begin{tabular}{lrr}
\hline & Current asthma & No current asthma \\
\hline More than 12 attacks of wheeze & $66 / 461(14 \cdot 3)$ & $12 / 4062(0 \cdot 3)$ \\
Sleep disturbed at least once a week & $148 / 454(32 \cdot 6)$ & $67 / 4058(1 \cdot 7)$ \\
Wheeze preventing speech & $100 / 460(21 \cdot 7)$ & $33 / 4061(0 \cdot 8)$ \\
Night cough at least once a week & $152 / 453(33 \cdot 6)$ & $204 / 3942(5 \cdot 2)$ \\
Exercise limited by cough or wheeze most times & $120 / 454(26 \cdot 4)$ & $50 / 3998(1 \cdot 3)$ \\
Usually chesty with colds & $286 / 466(61 \cdot 4)$ & $340 / 4013(8 \cdot 5)$ \\
\hline
\end{tabular}

Table 2 Prescribed treatment according to regular carer; figures are number (\%)

\begin{tabular}{lccc}
\hline & Hospital & General practitioner & None \\
\hline Inhaled $\beta$ agonist & $26(96 \cdot 3)$ & $129(92 \cdot 1)$ & $119(81 \cdot 5)$ \\
Inhaled sodium cromoglycate & $4(14 \cdot 8)$ & $32(22 \cdot 9)$ & $35(24 \cdot 0)$ \\
Inhaled steroid & $17(63 \cdot 0)$ & $80(57 \cdot 1)$ & $47(32 \cdot 2)$ \\
Methylxanthines & $2(7 \cdot 4)$ & $7(5 \cdot 0)$ & $3(2 \cdot 1)$ \\
Oral long acting $\beta$ agonist & $2(7 \cdot 4)$ & $5(3 \cdot 6)$ & $5(3 \cdot 4)$ \\
$\beta$ Agonist syrup & 0 & $8(5 \cdot 7)$ & $23(15 \cdot 8)$ \\
No inhaled prophylaxis & $4(14 \cdot 8)$ & $31(22 \cdot 1)$ & $60(41 \cdot 1)$ \\
Total & 27 & 140 & 146 \\
\hline
\end{tabular}

\section{STATISTICS}

Distributional differences were assessed by $\chi^{2}$ testing. Differences in morbidity scores between different groups were assessed by Mann-Whitney test for two groups, and by the Kruskal-Wallis test where there were three groups.
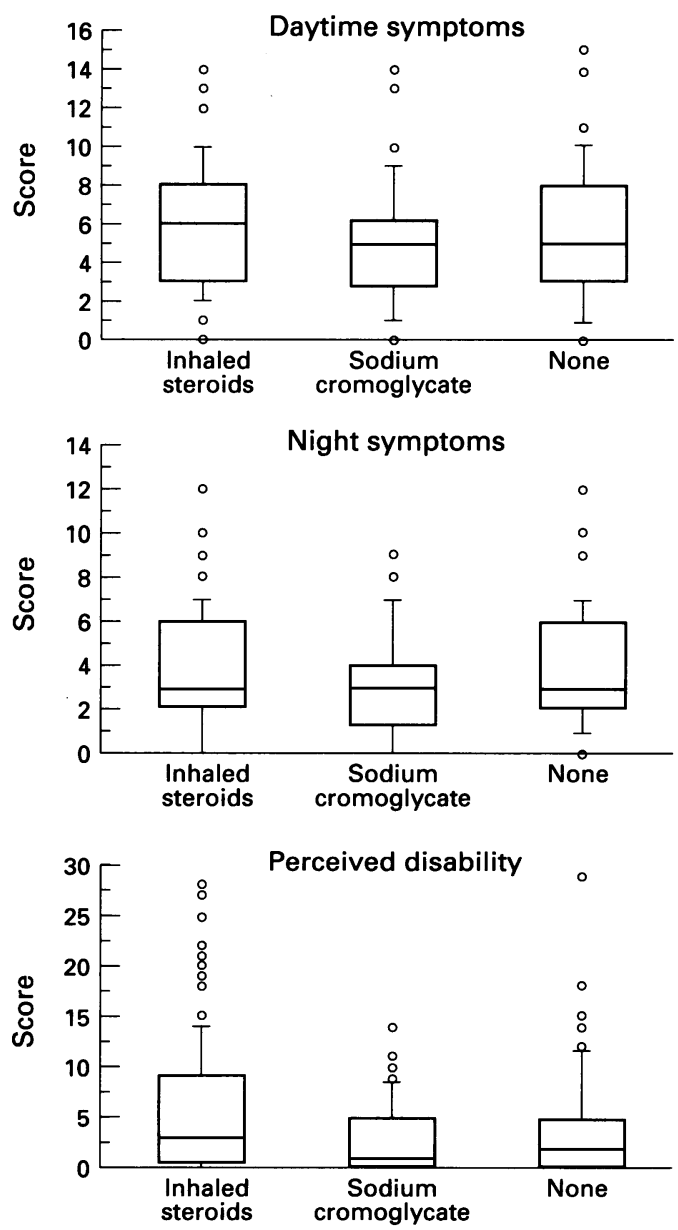

Day and night time symptom scores and perceived disability scores in children with asthma using different prophylactic inhalers. Boxes show median (interquartile range); bars are 10th centiles, with outliers shown.

\section{Results}

PRELIMINARY SURVEY

All primary schools in Sheffield were asked to participate in the preliminary survey; $129 / 131$ agreed to take part. Questionnaires were sent to the parents of all 5321 eligible children and $4539(85.3 \%)$ replied. A current diagnosis of asthma was reported in $466(10.3 \%)$ of the responders, of whom $256(54.9 \%)$ were boys. The proportion of boys in this group was not significantly different to that of the remainder $(50 \cdot 7 \%)$. A total of $771(17 \cdot 0 \%)$ reported wheeze in the last 12 months, while 1376 $(30.3 \%)$ had wheezed at some stage in their life. Of the children who had wheezed in the last 12 months, $401(52.0 \%)$ had a current diagnosis of asthma. Among the 461 children with asthma who gave details of attack frequency, $65(14 \cdot 1 \%)$ reported no wheezing attacks in the preceding 12 months, 152 $(33.0 \%)$ had one to three attacks, $178(38.6 \%)$ had four to 12 attacks, and $66(14.3 \%)$ had more than 12 attacks. Details of the pattern and frequency of symptoms reported by the parents are shown in table 1.

If the presence of wheeze on more than three occasions in the last 12 months, exercise induced cough or wheeze 'most times', or nocturnal cough or wheeze at least once a week are taken as symptoms suggestive of asthma, there were $287(6.4 \%)$ children in our survey with undiagnosed asthma. If children with any wheeze in the last 12 months were included, then the number increased to $484(10 \cdot 7 \%)$.

\section{DETAILED ASTHMA MORBIDITY SURVEY}

These 466 children were asked to participate in the asthma survey, and $336(72 \cdot 1 \%)$ responded, comprising 310 who completed and returned both the morbidity and the self esteem questionnaire, a further 17 who returned only the morbidity questionnaire, and nine who returned only the self esteem portion.

In the entire survey, the median (interquartile range) symptom score on the morbidity questionnaire was 11 (7-19). Median subscores were: day symptoms 6 (3-8), night symptoms $3(2-6)$, and perceived disability 2 $(0-6)$. At least one daytime symptom occurring every day or most days was reported in $105 / 327(32 \cdot 1 \%)$ of the responders. Although 50 children $(15 \cdot 3 \%)$ had at least one night symptom every night or most nights, only 16 $(4.9 \%)$ were reported as being woken regularly by the symptoms. Only five children $(1.5 \%)$ reported no symptoms in the preceding three months. Four were under regular review by the general practitioner, and three were taking regular inhaled steroid treatment.

In the 313 children where details were given, the regular care of the child's asthma was undertaken by the hospital in $27(8.6 \%)$ and by regular general practitioner review in 140 $(44 \cdot 7 \%)$. However, $146(46 \cdot 6 \%)$ reported that no regular review of their asthma took place. Table 2 shows the type of treatment reported according to the regular care given. Children not attending regular review were less likely to 
Table 3 Parental worry and regular preventive treatment; figures are number (\%)

\begin{tabular}{lcccccc}
\hline \multicolumn{7}{l}{ 'I worry about my child's health ...' } \\
\cline { 2 - 7 } Prophylaxis & Every day & Most days & Some days & A few days & Not at all & Total \\
\hline None & $5(5 \cdot 3)$ & $8(8 \cdot 4)$ & $35(36 \cdot 8)$ & $29(30 \cdot 5)$ & $18(18 \cdot 9)$ & 95 \\
Sodium cromoglycate & $6(11 \cdot 1)$ & $5(9 \cdot 3)$ & $21(38 \cdot 9)$ & $12(22 \cdot 2)$ & $10(18 \cdot 5)$ & 54 \\
Inhaled steroid & $27(21 \cdot 3)$ & $16(12 \cdot 6)$ & $48(37 \cdot 8)$ & $22(17 \cdot 3)$ & $14(11 \cdot 0)$ & 127 \\
Total & $38(13 \cdot 8)$ & $29(10 \cdot 5)$ & $104(37 \cdot 7)$ & $63(22 \cdot 8)$ & $42(15 \cdot 2)$ & 276 \\
\hline
\end{tabular}

Inhaled steroids significantly different: $\chi^{2}=18 \cdot 4,8 \mathrm{df}, \mathrm{p}<0.05$.

be taking inhaled prophylaxis (largely due to the much lower likelihood of taking inhaled steroids), and more likely to receive oral salbutamol syrup.

The figure shows the morbidity subgroup scores according to the type of prophylactic inhaler. There was no significant difference in objective day or night symptom scores between children on inhaled steroids, sodium cromoglycate, or no regular treatment. Despite this, there was a significantly higher perceived disability score $\left(\chi^{2}=7 \cdot 3,2 \mathrm{df}, \mathrm{p}<0.05\right)$ in children taking inhaled steroids, and the parents of these children worried about their child's health significantly more $\left(\chi^{2}=18 \cdot 4,8 \mathrm{df}\right.$, $\mathrm{p}<0.05)$, as shown in table 3 .

There were 88 children who reported symptoms of asthma (cough, wheeze, or breathlessness) every day or most days. Full data were available on treatment in 79 , and on place of care in 75. Although current guidelines recommend that all these children should receive regular prophylaxis, ${ }^{9}$ only $53(70 \cdot 7 \%)$ were receiving such treatment. Table 4 shows the use of prophylaxis according to place of care in these poorly controlled children. The likelihood of receiving prophylaxis was lowest in the group under no regular review, and highest in the hospital group $(p<0.01)$. There was no evidence that the group who did not receive prophylaxis had less severe symptoms as judged by overall symptom score $(z=0 \cdot 267$, $\mathrm{p}>0 \cdot 5$, Mann-Whitney U test).

The child's own self esteem, as rated by the Piers-Harris score, had a negative correlation with overall symptoms and with perceived disability scores. Although these correlations were significant $(p<0.001)$ they accounted for only $6 \%$ and $4.8 \%$ of the respective variances. The main subgroup cluster of the Piers-Harris score that was responsible for this correlation was cluster 4 (anxiety). Self esteem scores were unrelated to the type of prophylaxis used.

\section{Discussion}

This study aimed to assess all 8-9 year old children in a single school year diagnosed as having asthma. The $85 \%$ response rate to the first survey was comparable with previous

Table 4 Prescribed prophylaxis and place of care in regularly symptomatic asthmatic children; figures are number (\%)

\begin{tabular}{lclc}
\hline & Prophylaxis & No prophylaxis & Total \\
\hline Hospital & $8(100 \cdot 0)$ & 0 & 8 \\
General practitioner & $30(78 \cdot 9)$ & $8(21 \cdot 0)$ & 38 \\
None & $16(55 \cdot 2)$ & $13(44 \cdot 8)$ & 29 \\
Total & 45 & 21 & 75 \\
\hline
\end{tabular}

studies. $^{3} 1011$ The results from this survey show a significant morbidity in these children, with over one fifth having suffered speech limiting wheeze in the last 12 months, and over one quarter having regular exercise limitation. A small number of children in the remainder of the population were reported to have similar symptoms. These children probably represent undiagnosed asthmatics. Although the percentages are small, it is of concern that 33 children in our survey who were not recognised as asthmatic had had at least one attack of speech limiting wheeze in the previous year. Undiagnosed asthma is difficult to assess accurately, as the criteria for diagnosis are not agreed. A conservative estimate, using respiratory symptoms of sufficient frequency to have an impact on life, was that $6.4 \%$ of the surveyed children had undiagnosed asthma, giving an overall asthma prevalence of $16.7 \%$, increasing to $21 \%$ if all children who wheezed in the previous 12 months are included. Although undiagnosed asthma is still a problem, the scale of the problem appears much less than that reported in Newcastle in the 1970s. ${ }^{12}$

We have looked in more detail at the children with a diagnosis of asthma, using standardised and validated questionnaires. When the non-responders in the second survey were excluded it is likely that only about $60 \%$ of all eligible children with asthma were studied. There may be a selection bias in that children with more severe symptoms are more likely to reply to such questionnaires. With these caveats, the data permit an assessment to be made of the community morbidity from asthma, and internal comparisons between groups are still valid.

One of the major difficulties in the epidemiological study of asthma is case definition. The lack of a gold standard for asthma continues to cause difficulties in interpretation of questionnaire based or bronchial hyperreactivity (BHR) data from community populations. ${ }^{13}$ Our study used the core questions from the ISAAC questionnaire to standardise the data obtained. This questionnaire inquires into the prevalence and severity of wheezing illness and other recurrent respiratory symptoms such as night cough, daytime cough, or exercise induced symptoms. ${ }^{7}$ It also asks the question 'Has your child ever had asthma?' and a supplementary question used in this national survey (not part of the core questions): 'Has your child ever been diagnosed by a doctor as having asthma?' Case identification based on responses to the two asthma questions may be inaccurate as they will be affected by a number of factors: parental recall, physician diagnosis, and parental acceptance. ${ }^{14}$

An alternative suggestion is to use challenge tests of BHR and use 'symptomatic bronchial hyperreactivity' as a working definition for current asthma, that is those children with a 12 month period prevalence of wheeze on questionnaire and BHR on inhalation challenge tests. ${ }^{15} \mathrm{We}$ did not use tests of BHR in this study for two reasons. Firstly, there are concerns about tests for BHR as markers for 
asthma in community populations as many children will have reactivity but no current symptoms and children with symptoms may not demonstrate hyperreactivity. 111617 There may also be great variation in BHR within an individual over time. ${ }^{1819}$

Taking these difficulties into consideration, it is reassuring that the data from the national survey ${ }^{7}$ show similar prevalences. The national study was performed contemporaneously with our initial screening questionnaire, using the same methodology. It received 5472 questionnaire responses for children aged 5-17, and reported a $15 \%$ period prevalence of wheeze in the previous 12 months, compared with the prevalence of $16.9 \%$ in our study. Of those children who wheezed in the previous 12 months, $54 \cdot 4 \%$ were labelled as having asthma in the national study compared with $52 \%$ in our study. The severity of attacks and speech limiting attacks were also very similar in the two studies. Comparing data from other asthma prevalence studies is difficult because of the different methodology and definitions of asthma used.

In the second phase of our study we regarded children as having asthma if the parents reported a current diagnosis of asthma. We were assessing the morbidity and symptomatology reported in children with asthma, and to have a selection criterion that was based on symptoms would have made the study self fulfilling. As all but five of the children with asthma reported respiratory symptoms in the preceding three months, and three of these were on regular inhaled steroids, we feel that it is unlikely that there is a major problem with overdiagnosis in our population.

Most studies of asthma morbidity in childhood have focused on school absence as an objective measure of impact. We did not attempt to address this again in our study. Parental ratings of the impact of asthma are difficult to quantify because of subjectivity in reporting. Our use of a standardised questionnaire reduces this to some extent, but will not completely overcome the problem. There are differences in objective measures of symptoms and those reported by parents or children, particularly when nocturnal symptoms are studied. ${ }^{20}$ Considerable variability has also been reported in the ability of children to assess their own bronchial obstruction. ${ }^{21}$ This raises the question of whether we should be trying to assess perceived morbidity or 'true' morbidity. Measures of true morbidity might include tape recordings of a child's sleep, or spirometric assessments. As asthma is a variable disease, such measurements would have to be made over weeks or months to have any meaning. This would be virtually impossible in a large scale community survey. School absence might be another indicator of morbidity, but many factors other than asthma can contribute to this, and schools do not record the reason for absence. We therefore relied on the parental assessment of school absence due to respiratory symptoms using a validated questionnaire. It is unlikely that these ratings overestimate the problem, as parental estimates of school absence due to wheeze have been shown to be consistently lower than recorded absence from all causes. ${ }^{11}$

A recent study in Sheffield looked in detail at subjective measures of family disturbance and found a high social cost of asthma in a small and selected group of children hospitalised for asthma. ${ }^{22}$ It is not possible to say how far these families differ both from other families with asthma, or indeed from the population at large. We have not gathered control data to assess respiratory morbidity or self esteem, but we have provided a representative and quantified picture of the care given to children with diagnosed asthma in our community.

It is important to remember that only a small proportion of the most symptomatic asthmatics are under hospital review. This makes community surveys the only representative method of assessing the morbidity associated with asthma. It is all the more disappointing that the morbidity experienced by children in our survey is so high. The presence of symptoms every day or most days would generally be taken as an indicator of poor control, and yet almost one third of our population reported this finding. One in six children had nocturnal symptoms, although in the majority these were not reported to awaken them. Even in stable asthma, nocturnal symptoms have been shown to reduce the quality of sleep, and impair cognitive performance. ${ }^{23}$

The high morbidity seen, even in children reported to be receiving regular prophylaxis, does not necessarily imply that the medications are ineffective or prescribed in inadequate dosage. It is likely that some of the morbidity is due to poor compliance with treatment. ${ }^{24}$

When we compared the morbidity subscores in different treatment groups, we found that there was a discrepancy between symptom scores and the parental perception of disability. Children on regular inhaled steroids had a higher perceived disability score despite having similar symptoms to the other groups. In addition, parents were more worried about children who were on regular prophylactic inhalers, particularly inhaled steroids, despite the similarity in symptoms in different treatment groups. It could be argued that these increases in worry and perceived disability are consequences of the child requiring a regular inhaler. It seems equally likely that the level of treatment received by the child is determined to a considerable extent by the parental tolerance of the child's symptoms. It is not clear from our study whether the parents with a low tolerance of symptoms are likely to have children with a better or worse outcome. Parents of children with asthma show some positive adaptation in their perception of the disease, ${ }^{25}$ but our data show that this varies considerably with individuals.

It is reassuring that the parental perception of disability had such a small relationship to the child's self esteem. Less than $5 \%$ of the variance in self esteem was explained by parental perceptions of disability, and asthma 
symptoms themselves were only slightly more important as a predictor of self esteem.

In conclusion, we have shown that in a community survey of 8-9 year old children with asthma the reported morbidity is unacceptably high. The parental perception of the disease is more closely related to the level of treatment than to the level of symptoms. We suggest that the level of treatment is determined by the parental tolerance of symptoms as much as by the symptoms themselves.

This work was supported by a grant from the Sheffield Asthma Society.

1 Eiser C. Chronic childhood disease: an introduction to psychological theory and research. Cambridge: Cambridge University Press, 1990.

2 Peckham C, Butler N. A national study of asthma in childhood. 7 Epidemiol Community Health 1978; 32: 79-85.

3 Anderson HR, Bailey PA, Cooper JS, Palmer JC, West S. Morbidity and school absence caused by asthma and wheezing illness. Arch Dis Child 1983; 58: 777-84.

4 Lenney W, Wells NEJ, O'Neill BA. Burden of paediatric asthma. European Respiratory Review 1994; 4 (18): asthma.

5 Powell CVE, Primhak RA. The prevalence of recurrent respiratory symptoms in 8-9 year old schoolchildren. Thorax 1993; 48: 451A.

6 Usherwood TP, Scrimgeour A, Barber JH. Questionnaire to measure perceived symptoms and disability in asthma. Arch Dis Child 1990; 65: 779-81.

7 Strachan DP, Anderson HR, Limb ES, O'Neill BA, Wells N. A national survey of asthma prevalence, severity, and treatment in Great Britain. Arch Dis Child 1994; 70: $174-8$.

8 Piers EV. Piers-Harris children's self-concept scale. Los Angeles: Western Psychological Services, 1984.

9 Statement by the British Thoracic Society. Guidelines on the management of asthma in adults and children. Thorax 1993; 48: S1-24.

10 Hill $R$, Williams J, Britton J, Tattersfield A. Can morbidity associated with untreated asthma in primary school children be reduced? A controlled intervention study. BMF 1991; 303: 1169-74

11 Clifford RD, Radford $M$, Howell JB, Holgate ST. Prevalence of respiratory symptoms among 7 and 11 year old schoolchildren and association with asthma. Arch Dis Child 1989; 64: 1118-25.

12 Speight A, Lee D, Hey E. Underdiagnosis and undertreatment of asthma in childhood. BMF 1983; 286: 1253-6.

13 Anderson HR. Is the prevalence of asthma increasing? Paediatric Respiratory Medicine 1993; 1: 6-10.

14 Woolcock AJ. Epidemiological methods for measuring prevalence of asthma. Chest 1987; 91: S89-92.

15 Toelle BG, Peat JK, Salome CM, Mellis CM, Woolcock AJ. Toward a definition of asthma for epidemiology. Am Rev Toward a definition of asthma

16 Salome CM, Peat JK, Britton WJ, Woolcock AJ. Bronchial hyperresponsiveness in two populations of Australian schoolchildren. I. Relation to respiratory symptoms and diagnosed asthma. Clinical Allergy 1987; 17: 271-81.

17 Pattemore PK, Asher MI, Harrison AC, Mitchell EA, Rea HH, Stewart AW. The interrelationship among bronchial hyperresponsiveness, the diagnosis of asthma, and asthma symptoms. Am Rev Respir Dis 1990; 142: 549-54.

18 Josephs LK, Gregg I, Mullee MA, Holgate ST. Nonspecific bronchial hyperreactivity and its relationship to the clinical expression of asthma. Am Rev Respir Dis 1989; 140: 350-7.

19 Clough JB, Williams JD, Holgate ST. Profile of bronchial responsiveness in children with respiratory symptoms. Arch Dis Child 1992; 67: 574-9.

20 Archer LNJ, Simpson $H$. Night cough counts and diary card scores in asthma. Arch Dis Child 1985; 60: 1001-4.

21 Fritz GK, Klein RB, Overholser JC. Accuracy of symptom perception in childhood asthma. F Dev Behav Pediatr 1990; 11: 69-72.

22 Nocon A. Social and emotional impact of childhood asthma. Arch Dis Child 1991; 66: 458-60.

23 Fitzpatrick MF, Engleman H, Whyte KF, Deary IJ, Shapiro CM, Douglas NJ. Morbidity in nocturnal asthma: sleep quality and daytime cognitive performance. Thorax 1991; 46: 569-73.

24 Shope JT. Medication compliance. Pediatr Clin North Am 1981; 28: 5-21.

25 Donnelly JE, Donnelly WJ, Thong YH. Parental perceptions and attitudes toward asthma and its treatment: a controlled study. Soc Sci Med 1987; 24: treatm 